\title{
Ultrasonic Testing Combined with Pattern Recognition for the Detection of Kissing Bonds
}

\author{
Jens Schuster1, David Müller ${ }^{1}$, Ming-Hong Chen ${ }^{2}$, Quentin Govignon² \\ ${ }^{1}$ Institute for Polymer Technology West-Palatinate, University of Applied Sciences Kaiserslautern, Pirmasens, Germany \\ ${ }^{2}$ Institut Clément Ader, École des Mines d’Albi, Albi, France \\ Email: jens.schuster@hs-kl.de
}

How to cite this paper: Schuster, J., Müller, D., Chen, M.-H. and Govignon, Q. (2019) Ultrasonic Testing Combined with Pattern Recognition for the Detection of Kissing Bonds. Open Journal of Composite Materials, 9, 260-270.

https://doi.org/10.4236/ojcm.2019.93015

Received: May 7, 2019

Accepted: July 7, 2019

Published: July 10, 2019

Copyright (c) 2019 by author(s) and Scientific Research Publishing Inc. This work is licensed under the Creative Commons Attribution International License (CC BY 4.0).

http://creativecommons.org/licenses/by/4.0/

\begin{abstract}
Kissing bonds are defects in the adhesive bonds with intimate contact of touching surface but considerably lowered shear strength. Their detection specifically in the aerospace area is so not satisfactory. Usually, kissing bonds are inconspicuous in ultrasonic C-scans. However, the determination of attributes in the time domain and the frequency domain of an ultrasound signal provides the opportunity to derive a pattern for bonded area. Deviations from the pattern found in inconspicuous bonding areas indicate kissing bonds. The survey described here deals with the manufacturing of adhesively joint samples that purposefully include kissing bonds, as well as potential solutions for detecting them through ultrasonic testing combined with pattern recognition. The properties of the epoxy-based adhesive were varied by changing the mixing ratios between resin and hardener. Samples with a mixing ratio far apart from the manufacturer's recommendation with an inconspicuous appearance in a C-scan, but low shear strength values were taken for further evaluation. After a definition and learning phase, a 100 percent hit rate to separate good bondings from kissing bonds could be derived in a blind test. The discriminating feature found is due to the frequency shift between good and kissing bonds as well as the relative amplitude of the second peak.
\end{abstract}

\section{Keywords}

Ultrasonic Testing, Time Domain, Frequency Domain, Pattern Recognition, Bond Quality, Kissing Bond

\section{Introduction}

The increasing use of composites in aerospace, automotive, or other manufacturing industries demands the necessity to join polymer-based composite components. Riveting is traditionally used in aerospace industry, but it requires 
drilling holes and is a cause of stress concentrations and matting stresses which lead to an increased thickness and weight of the bonded area. In addition, holes do not agree well with the nature of polymer composites. The reason for using this joining technology also for composites, consists mainly of its exceptionally high reliability and the ease of control. Besides riveting, adhesives play an important role in joint technology. Compared to conventional techniques like welding and mechanical fastening, the adhesive bonding offers a number of advantages, such as uniform stress distribution, increased fatigue properties, a seal against liquids or gases, a reduction in structural weight, and connecting dissimilar materials [1]. However, there are several possible sources of weakness in adhesively bonded joints, such as gross flaws (cracks, voids, or porosities), poor cohesion, poor adhesion, and kissing bonds [2] [3] [4]. Therefore, non-destructive testing (NDT) methods are utilized to evaluate bonding integrity of the components unable to be destructively tested or in service. The ultrasonic inspection is one of the most promising NDT techniques for adhesive bonds. Most imperfections in adhesively bonded joints are generally identified by the use of standard ultrasonic testing, but not kissing bonds.

A kissing bond is a defect existing at a solid-solid interface with an intimate contact. It hides in localized spots surrounded by more-or-less well-bonded areas and is difficult to detect ultrasonically due to its low contrast in C-scans [5]. Additionally, kissing bonds cause a large reduction of bonding strength and an adhesive failure mode can be observed after it fractures [4] [6]. Thus, the occurrence of kissing bonds is in general not acceptable for aircraft structure because it may lead to fatal catastrophes. Three criteria describe a kissing bond:

1) The shear strength in the region of the kissing bond is drastically reduced. Almost no shear stresses can be transferred.

2) Failure in the region of the kissing bond is always adhesive.

3) Kissing bonds do not cause significant signals in a C-scan.

In order to better understand more of the interaction of ultrasonic waves, many studies have been focusing on the creation of artificial kissing bonds and the development of advanced ultrasonic techniques. Some references introduced a significantly thin layer of a contaminant into the interface between adherent and adhesive bonding joints [4] [5] [7] or plies of composite laminates [8] [9]. Oil, grease, and release film/agents have been used as such very often. Some authors simulated the defective interface without any foreign materials, which is also called dry contact kissing bond [4] [10] [11] [12]. It can only be fabricated by compressing two flat surfaces very tightly, using a loading system.

Some researchers have concentrated on spectroscopic techniques to evaluate the weak points undetectable by conventional ultrasonic testing [13] [14]. Spectral responses computed by transfer function or Fast Fourier Transform (FFT) from the time domain can offer clear ultrasonic images and reduction of noise [15]. By means of selecting the discriminant features from the frequency spectrum, pattern recognition is developed to classify adhesively defective bonds. In addition, there are only a few investigations characterizing kissing bonds with 
ultrasonic spectroscopy [16] [17]. These investigations cited are hardly applicable out of the lab or on an aircraft, because they either demand additional means to load the component under inspection, use multiple transducers or need access to both surfaces. However, companies such as Airbus, are fond of a robust test procedure delivering a binary test result with "red" for a faulty bond and green for a good bond [18].

The aim of the research presented here is to provide basic guidelines for the development of such a test procedure.

\section{Experimental}

\subsection{Materials}

For the adherend, $5 \mathrm{~mm}$ thick PVC-panels (length $20 \mathrm{~cm}$, width $10 \mathrm{~cm}$ ) with a density of $1.35 \mathrm{~g} / \mathrm{cm}^{3}$ were used. The speed of sound measured was about 2200 $\mathrm{m} / \mathrm{s}$.

The adhesive was a two-part commercial product UHU with five minutes working life, called UHU-5 hereafter. The curing time prior to ultrasonic testing was 72 hours.

\subsection{Ultrasonic Device and Transducer}

In this project, ultrasonic evaluations were performed by means of an immersion pulse-echo system with a three-axes gantry system (USPC 3040S AIRTECH 4000) from the company Hillger as shown in Figure 1. A 5-MHz, 2-inch focal length, spherically focused longitudinal wave transducer from Panametrics/Olympus (VF-309) was utilized to inspect the specimens with adhesive bondings.

\subsection{Preparation of Samples}

UHU-5 was purposefully selected for these experiments due to its similar sound properties to PVC. The quantity of the adhesive for mixing was chosen to be as low as possible, because larger quantities of epoxy will cure faster than smaller quantities. This happens as the cure of epoxy is exothermic and temperature dependent, a larger quantity will therefore generate more heat, which will in turn accelerate further the reaction and thus decrease pot life. Once the viscosity is increased, it is more difficult to remove the air bubbles introduced during the mixing process.

Three grams of the mixture was applied to the bonding area after cleaning it with acetone. Half of the area of the lower adherend is used for bonding the two plates. On the other half, weights were placed in order to situate the specimen firmly in the water tank for the ultrasonic scanning process. The configuration of specimen is shown in Figure 2. After ultrasonic testing, the samples were cut into four subsamples with an area of $25 \times 25 \mathrm{~mm}^{2}$.

The optimum composition of UHU- 5 suggested by the manufacturer is $5: 5$ by weight and generally provides the strongest mechanical bond compared to 


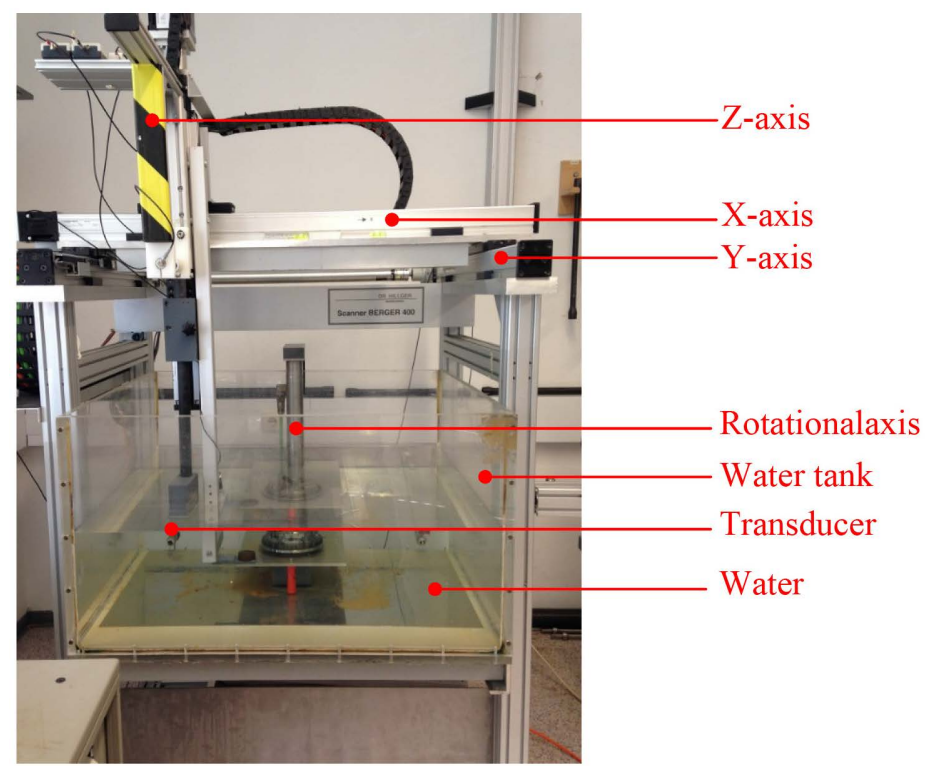

Figure 1. Ultrasonic device.

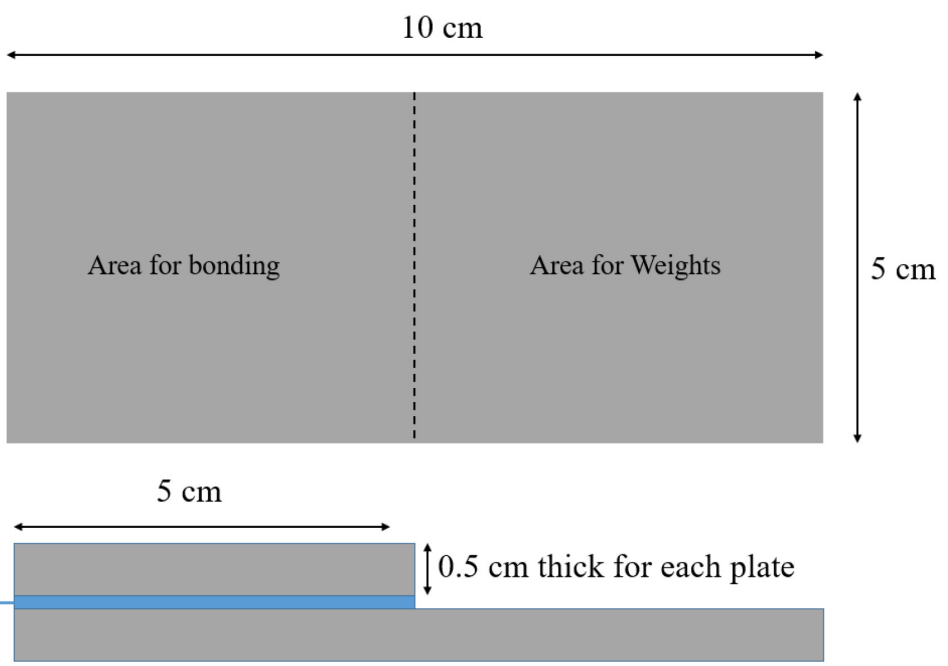

Figure 2. Top and side view of the specimen.

mixtures with other ratios. In order to create kissing bonds, nine different mix ratios of epoxy to hardener by weight were made, being 1:9, 2:8, 3:7, 4:6, 5:5, 6:4, $7: 3,8: 2$, and 9:1.

\subsection{Shear Tests}

An universal testing machine with a maximum force of 20,000 N from Zwick is used for material examination (Figure 3 ). The crosshead is set to a displacement speed of $5.0 \mathrm{~mm} / \mathrm{min}$ in compression. The test rig used and presented in Figure 3 is designed to induce shear loading of the bonded interface of the specimens. This specific test-rig is feasible for shear testing. Driven by the force coming from cross head acting compressively on a moveable test block which is guided by cylindrical guide bars, a shear test can be performed. It is also possible to see 


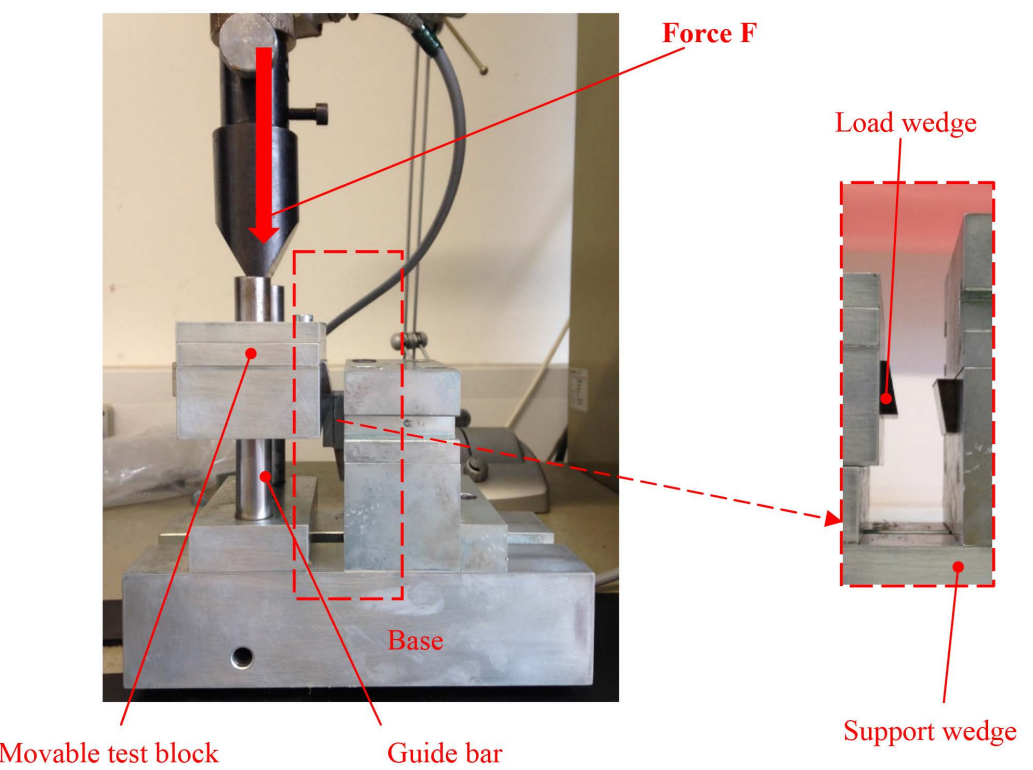

Figure 3. Shear device.

that the figure next to it illustrates the load and support wedge, which has the capability of clamping the specimen firmly, prior to testing. The loading and support wedges are presented in the close-up view. The $24.5 \mathrm{~mm}$ wide adjustable wedges are adjusted to stick out of the blocks by half of the specimen thickness ( $5 \mathrm{~mm}$ in our case), and the support block is adjusted to between the movable and support block. The base on the bottom gives the rig a stable foundation, leading to the integrity of the specimens during testing. The shear strength $\tau$ is calculated as the quotient between the force F and the sheared area of $25 \times 25$ $\mathrm{mm}^{2}$.

\subsection{Ultrasonic Testing}

A C-scan image of each mixture was generated by evaluating the highest amplitudes of the reflected signals in a gate with a width of $1 \mu \mathrm{m}$ set around the interface between the adhesive and adherend. The step width was $0.3 \mathrm{~mm}$ and the scanning speed was $25 \mathrm{~mm} / \mathrm{s}$. The gain was set to $37.5 \mathrm{~dB}$. The 1:9 and 9:1 mixtures did not cure properly. Thus, they were discarded from further investigations due to the elementariness of identification of the weak bond.

Besides the evaluation of ultrasound in the time domain, the device used makes it possible to analyze the frequency domain information. This information was used for pattern recognition.

\section{Results and Discussion}

\subsection{Ultrasonic Testing}

In Figure 4 the $\mathrm{C}$-scan results are clearly seen to be bright yellow at the mixtures of 5:5, 6:4, and 7:3; the 8:2 mixture being partial yellow and partial brown. In comparison, the 6:4 and 7:3 mixtures are mostly colored brown. Furthermore, the 2:8 mixture is displayed in pink in the $\mathrm{C}$-scan, which reveals that there is a 


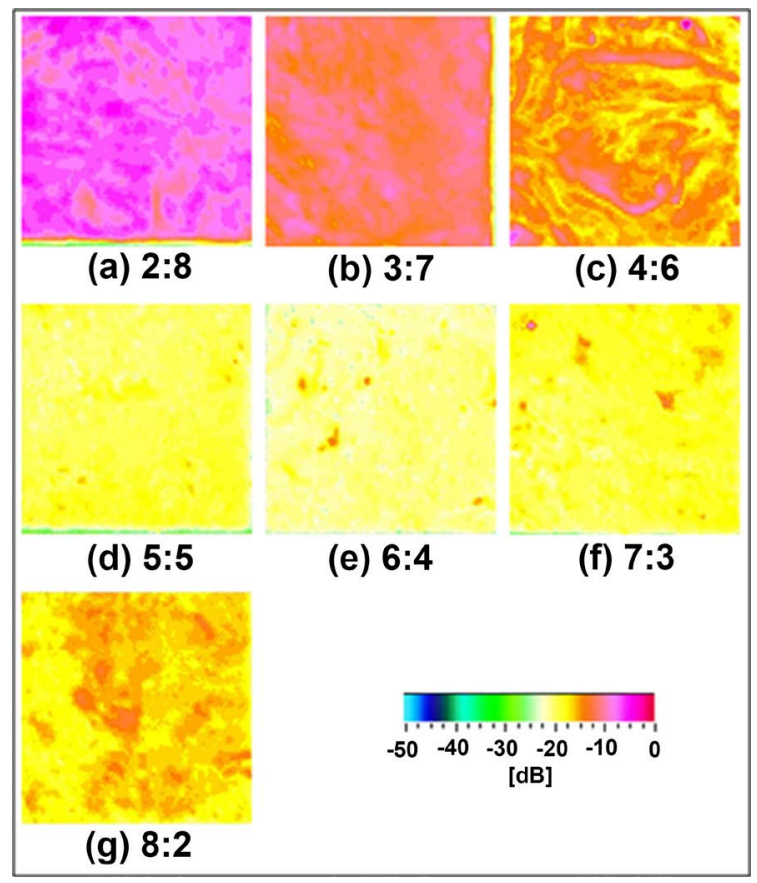

Figure 4. C-scans of interfaces with different ratios of resin and hardener.

strong interface signal in the A-scan, as well as implying the lowest degree of cure. Due to the similar results of the mixtures 5:5, 6:4, and 7:3, it is necessary to get more information from shear testing to see at which mixture the shear strength diminishes significantly compared to good bonds.

\subsection{Shear Tests}

The results obtained are shown in Table 1.

The optimal epoxy: hardener ratio of 5:5 reached a maximum average shear stress of $3.74 \mathrm{~N} / \mathrm{mm}^{2}$. It was considered as reference, in order to evaluate how much shear stress the other mixtures drop in percentage. The lowest shear stress is located at the ratio of $2: 8$ where the shear stress is less than $0.03 \mathrm{~N} / \mathrm{mm}^{2}$, the result of being incapable of resisting against the weight of the upper test block $(17 \mathrm{~N})$

Due to the previously mentioned characteristics of a kissing bond with no indication on a C-scan and a significant drop in shear strength, the 7:3 mixture was chosen as the proper ratio for producing kissing bonds.

\subsection{Pattern Recognition}

The received amplitudes-time-courses in the time domain were transformed continuously to frequencies-time-courses in the frequency domain by means of Fast Fourier Transformation (FFT).

Generally, the analysis of the frequency spectrum involves the following steps:

1) Generation of the signals in time domain;

2) Selection of the received signals to be analyzed; 
Table 1. Average value of shear stress for each mixture.

\begin{tabular}{cccc}
\hline $\begin{array}{c}\text { Epoxy:Hardener } \\
\text { Ratio }\end{array}$ & $\begin{array}{c}\text { Max. Shear Stress } \\
\square \max [\mathrm{MPa}]\end{array}$ & $\begin{array}{c}\text { Standard deviation } \\
{[\mathrm{MPa}]}\end{array}$ & $\begin{array}{c}\text { Drop in Shear } \\
\text { Strength [\%] }\end{array}$ \\
\hline $2: 8$ & $<0.03$ & - & 99.2 \\
$3: 7$ & 0.95 & 0.43 & 74.5 \\
$4: 6$ & 2.97 & 0.20 & 20.6 \\
$5: 5$ & 3.74 & 0.44 & - \\
$6: 4$ & 3.39 & 0.08 & 9.3 \\
$7: 3$ & 1.95 & 0.17 & 47.9 \\
$8: 2$ & 1.81 & 0.46 & 51.6 \\
\hline
\end{tabular}

3) Execution of the Fast Fourier Transform (FFT);

4) Display of frequency domain information;

5) Features selection and analysis.

As stated in the previous chapter, the mixture 5:5 led to a good bond specimen with the highest peak shear stress, and the mixture 7:3 was considered as a kissing bond owing to large reduction of shear stress and undetectable in C-scan. In order to be able to differentiate between them, ten specimens were prepared for each mixture. All these specimens were ultrasonically inspected by manually moving the transducer over each of the nine points of inspection as shown in Figure 5.

The information from time domain was gathered. The received signals from the interface echo were analyzed after their transformation into the frequency domain. Since the amplitudes are not only depending on the signal itself but also on the amplification, the gain was set to $37.5 \mathrm{~dB}$ for making comparisons.

The representations of the mixtures in time and frequency domain are shown in Table 2 where, two characteristic amplitude-time courses and frequency-time courses are depicted.

Their quantitative features in the frequency spectrum are listed in Table 3. It can be observed that two peaks exist for both mixtures. Also, the difference can be seen between the two mixtures with 5:5 mixture having a higher peak and secondary peak frequency occurring around $2.10 \mathrm{MHz}$ and between 4.5 to 5.0 $\mathrm{MHz}$, respectively. The peaks for the 7:3 mixture are at approximately $1.90 \mathrm{MHz}$ and between 3.7 to $4.2 \mathrm{MHz}$. It can be interpreted as the attenuation of causing a reduction of sound wave frequency. While the ultrasound wave is propagating through a medium, its energy loss depends on the elasticity of the medium. Furthermore, a disparity can be found with the 5:5 mixture having a lower relative amplitude of the second peak frequency varying from a range of 10 to 60 whereas the frequency distribution of the 7:3 mixture stretches from 60 to $99 \%$. The variations in amplitude may be due to the slight difference in the degree of cure. The reason that 7:3 mixture has a higher relative amplitude of the second peak frequency can be described by the interference at the defective interface where sound waves were partially transmitted partially through and the others were 


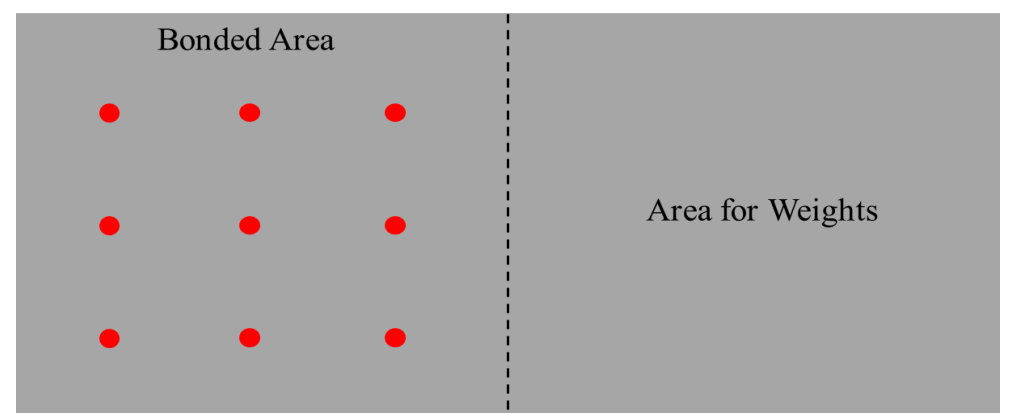

Figure 5. Inspected points (red) on bonded area of specimen.

Table 2. Representative of 5:5 and 7:3 mixtures in time and frequency domain.

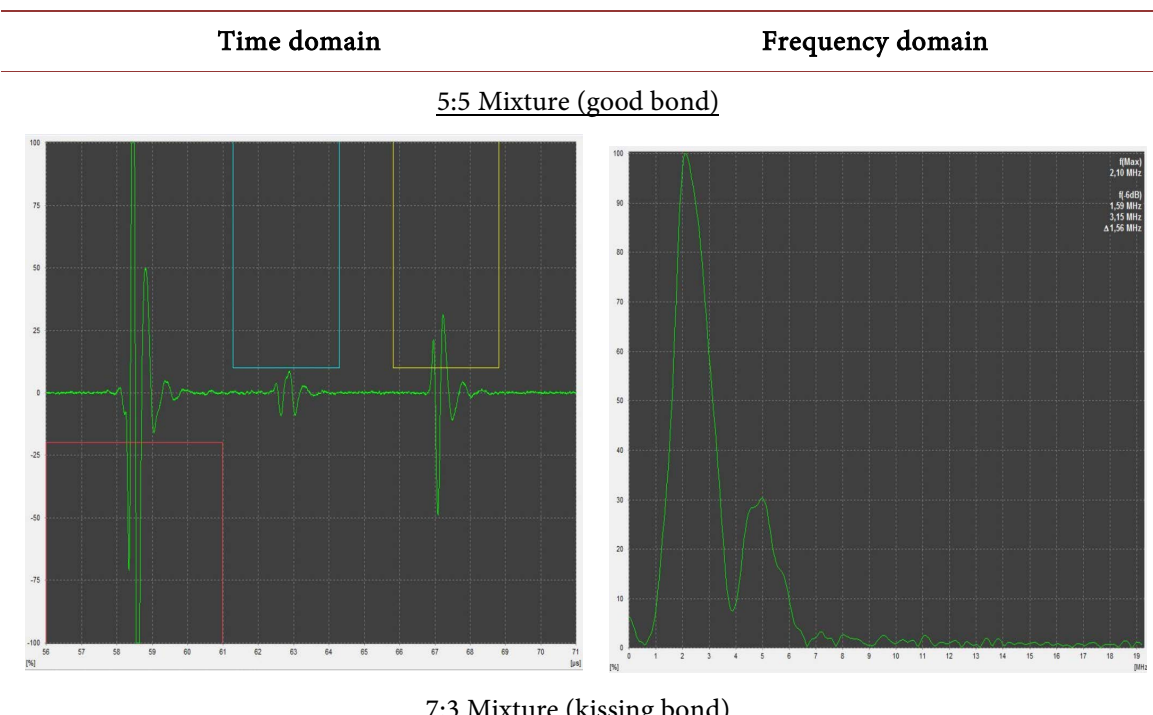

7:3 Mixture (kissing bond)

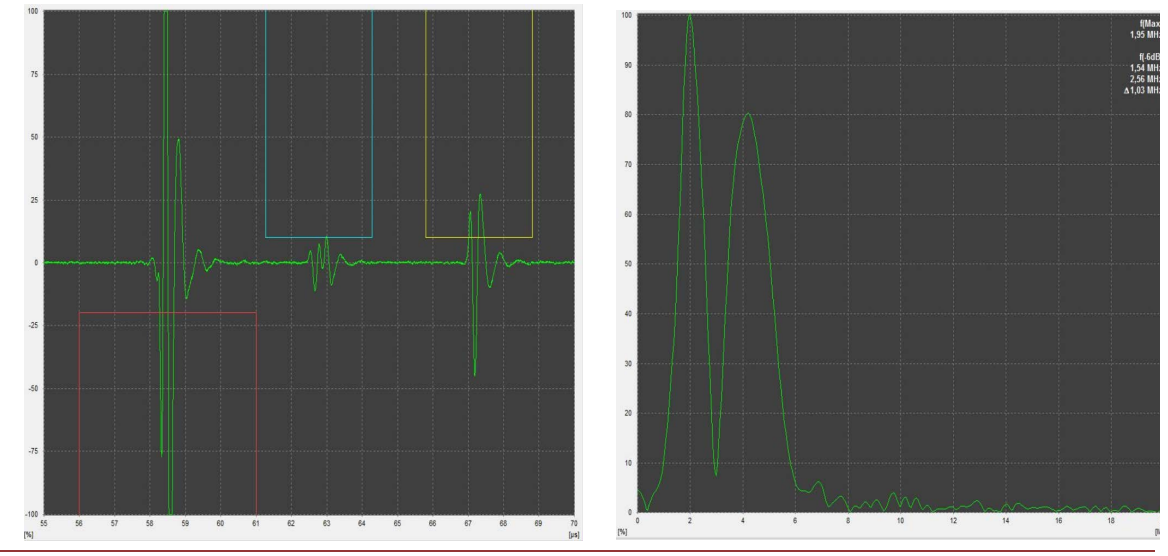

Table 3. Features in frequency spectrum of mixtures.

\begin{tabular}{ccc}
\hline Mixture & $\begin{array}{c}5: 5 \\
\text { (good bonds) }\end{array}$ & $\begin{array}{c}7: 3 \\
\text { (kissing bonds) }\end{array}$ \\
\hline Depression (recognizable) & 1 & 1 \\
Peak frequency (MHz) & $\sim 2.10$ & $\sim 1.95$ \\
Second peak frequency (MHz) & $4.5-5.0$ & $3.7-4.2$ \\
Relative amplitude of the second peak (\%) & $10-60$ & $60-99$ \\
\hline
\end{tabular}


partially reflected from [1]. This feature is a result of the superposition of the adherent-adhesive and adhesive-adherent interface echoes.

Furthermore, feature scans (F-scan) were performed to obtain the frequency distribution for both of mixtures. Feature scans work similar like C-scans but the image represents the major frequency distribution over the test sample with the UT-information transformed by real-time-FFT. Figure 6 displays F-scans for a good and a kissing bond revealing a good agreement with the peak frequency observed previously and shown in Table 3. Based on the color representation of each mixture, (corresponding to the color bar beneath the scans), it can be sated that the peak frequency of kissing bonds is lower than for the good bond.

According to the features found, the discriminating feature is due to the frequency shift between good and kissing bonds as well as the relative amplitude of the second peak.

\subsection{Qualification of Method}

To assess the reliability of the two discriminating features selected in the previous chapter the final task is to classify a set of unknown bond specimens with the features applied. To accomplish the purpose, 10 new specimens for each mixture were manufactured. They were mixed randomly prior to ultrasonic testing. For the evaluation, the discriminating features were employed to classify the specimens into good and kissing bonds. Finally, the reliability of the procedure was evaluated by measuring the shear strength. With regard to the experimental results, the established pattern recognition was $100 \%$ reliable in separating a set of 20 specimens into good and kissing bonds.

\section{Conclusions}

The aim of this study has been to develop a pattern recognition strategy to identify kissing bonds in adhesive joints. For this purpose, kissing bonds were

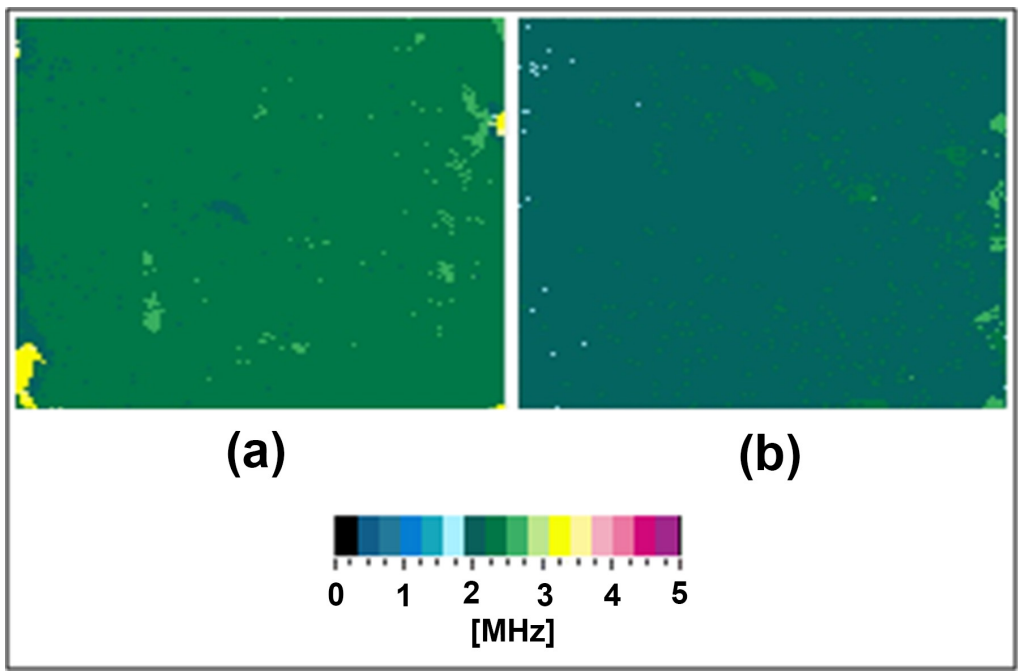

Figure 6. F-scan of (a) 5:5 Mixture (good bond), (b) 7:3 Mixture (kissing bond). 
manufactured by varying the mix ratios of a two-part adhesive. The adhesive has to be determined that it shall have a similar acoustic impedance to the adherend. Otherwise, a strong reflection amplitude of the interface would occur.

For the preparation of specimens, a proper and reliable adhesive mixing of the components is needed in order to minimize other defects such as voids. By doing so, it could reduce significantly the scattering of the ultrasound and is better for developing a pattern recognition approach.

From the results of pattern recognition, both good and kissing bonds have only a depression (between two recognizable peaks) in their frequency spectra. A peak frequency shift has been found comparing good bond and kissing bonds. Moreover, kissing bonds have a higher amplitude of the second peak frequency.

The frequency shift and the amplitude of the secondary peak were selected as a pattern recognition approach for distinguishing between good and kissing bonds with PVC-adherends and a specific adhesive. A reliability of $100 \%$ has been achieved by a blind test for this particular set-up. It is important to note that this pattern based approach of ultrasonic testing only works if the coupling conditions and all testing parameters remain the same at all times. Thus, research to evaluate the qualification, reliability, and robustness of this method for other adherend-adhesive combinations have to be faced in the near future.

\section{Conflicts of Interest}

The authors declare no conflicts of interest regarding the publication of this paper.

\section{References}

[1] Light, G.M. and Kwun, H. (1989) Nondestructive Evaluation of Adhesive Bond Quality. Report, Southwest Research Institute, San Antonio.

[2] Guyott, C.C.H., Cawley, P. and Adams, R.D. (1986) The Non-Destructive Testing of Adhesively Bonded Structure: A Review. Journal of Adhesion, 20, 129-159. https://doi.org/10.1080/00218468608074943

[3] Adams, R.D. and Cawley, P. (1988) A Review of Defect Types and Nondestructive Testing Techniques for Composites and Bonded Joints. NDT International, 21, 208-222. https://doi.org/10.1016/0308-9126(88)90333-1

[4] Brotherhood, C.J., Drinkwater, B.W. and Guild, F.J. (2002) The Effect of Compressive Loading on the Ultrasonic Detectability of Kissing Bonds in Adhesive Joints. Journal of Nondestructive Evaluation, 21, 95-104. https://doi.org/10.1023/A:1022584822730

[5] Jeenjitkaew, C. and Guild, F.J. (2017) The Analysis of Kissing Bonds in Adhesive Joints. Journal of Adhesion and Adhesives, 75, 101-107. https://doi.org/10.1016/j.ijadhadh.2017.02.019

[6] Alston, J., Croxford, A., Potter, J. and Blanloeuil, P. (2018) Nonlinear Non-Colinear Ultrasonic Detection and Characterization of Kissing-Bonds. NDT\&E International, 99, 105-116. https://doi.org/10.1016/j.ndteint.2018.07.003

[7] Chen, B.Y., Soh, S.K., Lee, H.P., Tay, T.E. and Tan, V.B.C. (2016) A Vibro-Acoustic Modulation Method for Detection of Delamination and Kissing Bond in Compo- 
sites. Journal of Composite Materials, 50, 3089-3104.

https://doi.org/10.1177/0021998315615652

[8] Tighe, R.C., Dulieu-Barton, J.M. and Quinn, S. (2013) Identification of Kissing Defects in Adhesive Bonds Using Infrared Thermography. International Journal of Adhesion and Adhesives, 42, 60-68. https://doi.org/10.1016/j.ijadhadh.2013.01.004

[9] Vijaya Kumar, R.L., Bhat, M.R. and Murthy, C.R.L. (2016) Evaluation of Kissing Bond in Composite Adhesive Lap Joints Using Digital Image Correlation. International Journal of Adhesion and Adhesives, 64, 168-178. https://doi.org/10.1016/j.ijadhadh.2015.10.018

[10] Delrue, S., Tabatabaeipour, M. and Hettler, J. (2016) Applying a Nonlinear, Pitch-Catch, Ultrasonic Technique for the Detection of Kissing Bonds in Friction Stir Welds. Ultrasonics, 68, 71-79. https://doi.org/10.1016/j.ultras.2016.02.012

[11] Poveromo, S.L. and Earthman, J.C. (2014) Analysis of "Kiss" Bonds between Composite Laminates. JOM, 66, 970-978. https://doi.org/10.1007/s11837-014-0956-5

[12] Yan, D., Drinkwater, B.W. and Neild, S.A. (2009) Measurement of the Ultrasonic Nonlinearity of Kissing Bonds in Adhesive Joints. NDT\&E International, 42, 459-466. https://doi.org/10.1016/j.ndteint.2009.02.002

[13] Brotherhood, C.J., Drinkwater, B.W. and Dixon, S. (2003) The Detectability of Kissing Bonds in Adhesive Joints Using Ultrasonic Techniques. Ultrasonics, 41, 521-529. https://doi.org/10.1016/S0041-624X(03)00156-2

[14] Kundu, T., Maji, A. and Gosh, T. (1998) Detection of Kissing Bonds by Lamb Waves. Ultrasonics, 35, 573-580. https://doi.org/10.1016/S0041-624X(97)00095-4

[15] Nagy, P.B. (1991) Ultrasonic-Detection of Kissing Bonds at Adhesive Interfaces. Journal of Adhesion Science and Technology, 5, 619-630. https://doi.org/10.1163/156856191X00521

[16] Thomas, G.H. and Rose, J.L. (1980) An Ultrasonic Evaluation and Quality Control Tool for Adhesive Bonds. Journal of Adhesion, 10, 293-316. https://doi.org/10.1080/0021846808544635

[17] Pavlopoulou, S., Worden, K. and Soutis, C. (2016) Novelty Detection and Dimension Reduction via Guided Ultrasonic Waves: Damage Monitoring of Scarf Repairs in Composite Laminates. Journal of Intelligent Material Systems and Structures, 27, 549-566. https://doi.org/10.1177/1045389X15574937

[18] Kruse, T. (2013) Bonding of CFRP Primary Aerospace Structures: Overview on the Technology Status in the Context of the Certification Boundary Conditions Addressing Needs for Development. Proceedings 19th International Conference on Composite Materials, Montreal, 28 July-2 August 2013, 5635-5643.

[19] Adams, R.D. and Drinkwater, B.W. (1997) Nondestructive Testing of Adhesively-Bonded Joints. NDT\&E International, 30, 93-98.

https://doi.org/10.1016/S0963-8695(96)00050-3 